\title{
Tarla Koşullarında Suni İnokulasyon ile Bazı Arpa Genotiplerinin Rhynchosporium commune (Zaffarano, Mc Donalds\&Linde) Arpa Yaprak Yanıklığı Hastalığına Karşı Reaksiyonlarının Belirlenmesi
}

\author{
Hakan HEKIMHAN ${ }^{I^{*}}$

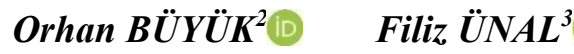 \\ Aydan $A R A Z^{4}$ (IC \\ Aysel YORGANCILAR ${ }^{5}$ \\ M. Erkut ÖZKESKİN \\ Asuman TORUN ${ }^{7}$ \\ Soner YÜKSEL ${ }^{8}$ \\ Esra ÇELIK ${ }^{9}$ \\ Suat KAYMAK ${ }^{10}$ \\ ${ }^{1}$ Ege Tarımsal Araştırma Enstitüsü, Menemen, İmir/TURKEY \\ 2,4,9 Zirai Mücadele Merkez Araştırma Enstitüsü, Ankara/TURKEY \\ ${ }^{3}$ Osmangazi Üniversitesi Ziraat Fakültesi, Bitki Koruma Bölümü, Eskişehir/TURKEY \\ 5,6,7,8 Geçit Kuşağı Tarımsal Araştırma Enstitüsü, Eskişehir/TURKEY \\ ${ }^{10}$ Tarımsal Araştırmalar ve Politikalar Genel Müdürlüğ̈̈, Bitki Să̆lı̆̆ı Araştırmaları \\ Daire Başkanlı̆̆ı, Ankara/TURKEY \\ ${ }^{1}$ https://orcid.org/0000-0002-6531-6490
${ }_{3}^{3}$ https://orcid.org/0000-0003-4620-5397
${ }^{5}$ https://orcid.org/0000-0002-9078-1685
${ }^{7}$ https://orcid.org/0000-0001-7269-4628
${ }^{9}$ https://orcid.org/0000-0002-5135-9123 \\ *Corresponding author (Sorumlu yazar): hakanhekimhan@hotmail.com \\ ${ }^{2}$ https://orcid.org/0000-0002-5424-3134 \\ ${ }^{4}$ https://orcid.org/0000-0002-6906-9351 \\ ${ }^{6}$ https://orcid.org/0000-0002-2362-6618 \\ ${ }^{8}$ https://orcid.org/0000-0002-0984-0765 \\ ${ }^{10}$ https://orcid.org/0000-0003-2773-1076
}

Received (Geliş tarihi): 16.10.2020Ａccepted (Kabul tarihi): 18.02.2021

ÖZ: Arpada yaprak yanıklı̆̆ etmeni olan Rhynchosporium commune (Zaffarano, Mc Donalds\&Linde), bitkide gelişmeyi olumsuz etkilemekte ve verimi önemli ölçüde düşürmektedir. Etmen, Türkiye'de arpanın en önemli hastalı etmenlerinden birisidir ve gelişmesine uygun koşullarda ürün kaybı \%10-40 olabilmektedir. Bu çalışma kapsamında, Türkiye'de yetiştirilen bazı arpa çeşitleri (63 adet) ve Eskişehir Geçit Kuşağı Tarımsal Araşstırma Enstitüsü’ne ait ileri kademe arpa hatları (46 adet) 3 tekerrürlü olarak tesadüf bloklart deneme deseninde Eskişehir'de 2017-2018 ve 2018-2019 sezonlartnda test edilmiştir. Testlerde $\boldsymbol{R}$. commune'nin 5 virülent izolatı karışım halinde tarla koşullarında bitkilere kardeşlenme dönemi sonusapa kalkma başlangıcında (Zadoks 30-39) bir hafta içerisinde üç kere uygulanmıştır. Bu çalışma sonucunda bazı arpa çeşit ve ileri kademe arpa hatlarının $\boldsymbol{R}$. commune'ye karsşı gösterdiği dayanıklılı reaksiyonları 1-9 skalasına göre belirlenmiştir. Alınan sonuçlara göre çeşitlerden \%2'si çok dayanıkll, \%8'i dayanıkl, \%33'ü hassas ve \%13'ü çok hassas bulunmuştur. Verim kademesindeki hatlardan ise \%12'si dayanıkl, \%55'i orta dayanıklı, \%33'ü hassas olarak belirlenmiş çok dayanıklı ve çok hassas düzeyde materyal tespit edilmemiştir. Reaksiyon çalı̧̧maları sonucunda hastalığa karşı dayanıklı bulunan arpa çeşit ve hatları gelecekte ıslah çalışmalarında dayanıklılık kaynağı olarak kullanılabilir ve dayanıklı çeşitler hastalığın sorun olduğu yörelerde ekilebilir. Dayanıkl velveya yüksek derecede toleranslı bulunan materyaller kontrollü koşullarda test edilerek ve moleküler çalışmalarla da desteklenerek ıslahta güvenilir bir şekilde kullanılabilirler.

Anahtar Kelimeler: Rhynchosporium commune (Zaffarano, Mc Donalds\&Linde), arpa yaprak yanıklığl, arpa, Hordeum vulgare $\mathrm{L}$., çeşit, hat, patotip, reaksiyon, inokulasyon, duyarlı, dayanıklı. 


\title{
Determination of the Reactions of some Barley Genotypes to Scald \\ [Rhynchosporium commune (Zaffarano, McDonald \& Linde)] under Field Conditions with Artificial Inoculation
}

\begin{abstract}
Rhynchosporium commune, leaf blight agent of barley, negatively affects plant growth and significantly reduces yield. The causal agent is one of the most important disease agent of barley in Turkey and yield loss under favourable conditions can be 10-40\%. In this study, 63 barley varieties grown in Turkey and 46 advanced barley lines of Transitional Zone Agricultural Research Instititute's materials were tested according to randomized complete block design with 3 replicates in growing seasons of 2017-2018 and 2018-2019 in Eskişehir Province. In the tests, 5 virulent isolates of R. commune were mixed and sprayed on plants from tillering to booting stage (Zadoks 30-39) at three times under the field conditions. As a result of these studies, resistance of some barley varieties and advanced lines against the disease was determined according to 1-9 scale. According to the results, 2, 8, 33 and 13\% of the varieties were found to be very resistant, resistant, susceptible and very susceptible, respectively. Among the advanced lines, 12, 55 and $33 \%$ were resistant, moderately resistant, and susceptible respectively, but neither very resistant nor very susceptible reaction was detected among the materials tested. As a result of the reaction studies, varieties and lines of barley that are resistant to the disease can be used as a source of resistance in future breeding studies and those varieties can be planted in areas where the disease is a problem. Resistant and/or highly tolerant materials can be reliably used in breeding by being tested under controlled conditions and supported by molecular studies.
\end{abstract}

Keywords: Rhynchosporium commune (Zaffarano, Mc Donalds\&Linde), scald, barley, Hordeum vulgare L., variety, advanced line, pathotype, reaction, inoculation, susceptible, resistant.

\section{GİRIŞ}

Dünyada yaygın olarak tarımı yapılan tahıl türleri arasında dördüncü sırada yer alan arpa (Hordeum vulgare L.), ülkemizde ekmeklik buğday (Triticum aestivum L.)'dan sonra en çok yetiștiriciliği yapılan tahıl türüdür. Türkiye'de tarım alanlarının \%66'sını tarla bitkileri oluşturmaktadır. Ülkemizde arpa 2019 yılında 28.690.715 dekarlık ekiliş alanı ve 7.600 .000 ton üretimi ile buğdaydan sonra ikinci sırada yer alan önemli bir tahıl türüdür (Anonim, 2020a). Buğdaya göre daha erkenci olması nedeniyle, düşük ve düzensiz yağış alan yerler için uygun bir bitkidir. Aynı zamanda buğdaya göre tuzluluğa ve alkaliliğe ve soğuk şartlara oldukça dayanıklıdır. Türkiye'de arpa üretiminin yüzde 90'1 hayvan yemi olarak, kalanı ise bira sanayinde ve gıda endüstrisinde kullanılmaktadır. Gıda endüstrisinde kullanılan oran çok düşük olup, bira sanayinde kullanılan oran her geçen y1l artmaktadır. (Başgül ve Engin, 1995; Anonim, 2006). Türkiye 2018 y1lında 655.988 ton 2019 y1lında ise 562.777 ton arpa ithalatı yapmıştır. Ayrica, 2018 yılinda 15.610 ton ve 2019 y1linda ise 41.188 ton ihracat gerçekleştirmiştir (Anonymous, 2020). Görüleceği üzere arpa üretimimiz yeterli değildir. Arpa üretiminde ve kalitesinde sağlanacak artış ile yem ve malt sanayinin ihtiyacı karşılanmış olacaktır. Dünyada olduğu gibi ülkemizde de tarım alanlarının sınırlı olması ve hızlı nüfus artışı ve çeşitli afetler nedeniyle gıda maddelerinin öneminin artması, tarımsal verimliliğin sürekliliğinin sağlanmasını zorunlu kılmaktadır (Birişik, 2020).

Hastalık, zararlı veya kuraklık gibi canlı ya da cansız stres etkenleri ile fotosentez alanının azalması, tane veriminde kayıplara neden olmaktadır (Gaunt ve Wright, 1992; Blum, 2018). R.commune'nin neden olduğu Arpa yaprak yanıklığı hastalığı, Dünya'nın çeşitli serin, nemli ve yarı nemli bölgelerinde olduğu gibi, Türkiye'de de arpanın en önemli yaprak hastalıklarından birisidir. Hastalık etmeni, genellikle kardeş sayısı ve tane ağırlığının azalması ile üründe eksilişlere neden olmaktadır (Zencirci ve Hayes, 1990). Verimde oluşacak kayıplar, hastalığın başladığı döneme bağlı olarak ülkemizde \%30-40'a kadar yükselebilmektedir (Kavak, 1998; Aktaş, 2001). Genel olarak hastalık etmeni nedeniyle dünyada \%10-70'lere varan oranlarda ürün kaybı bildirilmektedir (Mathre, 1982). Enfeksiyon zamanı ve özellikle üst yaprakların bulaştığı koşullar ürün kayıplarını artırmaktadır (Döken, 1979). İngiltere'de sahada, \% 1-10'luk kayıpların daha yaygın olduğu belirtilmekle birlikte $\%$ 40'a varan verim kayıpları rapor edilmiştir. Yalnızca Birleşik Krallık'ta, kimyasal fungisitler kullanımına rağmen tahmini olarak 10,8 milyon $£$ (225 £/ton fiyat varsayıldığında) ulusal verim 
H. HEKIMHAN, O. BÜYÜK, F. ÜNAL, A. ARAZ, A. YOGANCILAR, M. E. ÖZKESKİN, A. TORUN, S. YÜKSEL, E. ÇELIK, S. KAYMAK TARLA KOŞULLARINDA SUNI İNOKULASYON ILE BAZI ARPA GENOTIPLERININ Rhynchosporium commune (ZAFFARANO, MC DONALDS\&LINDE) ARPA YAPRAK YANIKLIĞI HASTALIĞINA KARŞI REAKSIYONLARININ BELIRLENMESI

kayıplarına neden olduğu belirtilmektedir (Anonymous, 2021).

Kültürü yapılan arpa ve diğer Hordeum spp. ve Bromus diandrus'u enfekte edebilen Rhynchosporium izolatları $R$. commune, çavdar ve tritikale'yi enfekte edebilen izolatlar Rhynchosporium secalis ve ayrık (Agropyron spp.) türlerini enfekte edebilen izolatlar ise Rhynchosporium agropyri olarak adlandırılmıştır (Avrova ve Knogge, 2012).

Buğdaygillerde hastalıklara neden olan beş Rhynchosporium türü $(R$. commune, $R$. secalis, $R$. agropyri, Rhynchosporium orthosporum ve Rhynchosporium lolii) saptanmıştır. $R$. commune; Hordeum murinum ssp. glaucum, Hordeum vulgare ssp. spontaneum, Lolium multiflorum ve Avena sativa'da saptanmıştır (Zaffarano ve ark., 2011; Seifollahi ve ark., 2020). Arpa yaprak yanıklığı hastalığı Türkiye'de ilk kez Bremer ve arkadaşlarınca tespit edilmiş ve yaygın olduğu belirtilmiştir (Göbelez, 1964).

Damgac1 (1981), 1980 y1lında Orta Anadolu bölgesinde yaptığı sürveylerde yaprak yanıklığı $(R$. commune) hastalığıyla bulaşıklık oranı ve şiddetinin sapa kalkma döneminde $\% 64,5$ ve $\%$ 5,6 ; süt olum döneminde $\% 49,7$ ve $\% 1,89$ olduğunu, ancak hastalık şiddetinin bazı tarlalarda aynı devrelerde sirasiyla \% 17,7 ve \% 12,5'e kadar çıkabildiğini bildirmiştir. Aktaş (1984), tarafından yürütülen bir çalışma sonucu hastalığın ülkemizde yaygın olarak görüldüğü, Orta Anadolu Bölgesinde ise bazı yıllarda büyük kayıplara sebep olduğu, hastalık şiddetinin \% $1-31$ oranında değiştiği bildirilmiştir. Mamluk ve ark. (1997) tarafından Orta Anadolu'da gerçekleştirilen sürveyler sonucunda 1993 yılında incelenen üretim alanlarının yarıdan fazlasında hastalığın görüldüğü ve bu alanların \% 20'sinde ürünün hastalıkla bulaşı olduğu belirlenmiştir. Kavak ve Katırcioğlu (1998) tarafindan yapılan bir çalışmada ise hastalık nedeniyle $\% 30,5$ verim kaybının olabileceği, Aktaş (2001) tarafindan hastalık nedeniyle kayıpların \%20'ye kadar çıkabileceği, bildirilmiştir.
Ülkemizde son y1llarda yapılan çalışmalarda Rhynchosporium secalis'in yaygınlığı Eskişehir ilinde \% 22.07 (Çelik ve Karakaya, 2015), Ege sahil kuşağında \%35 (Hekimhan ve ark., 2016a), Aksaray ilinde \%16,16 (Eğilmez ve Boyraz, 2019) olarak tespit edilmiştir. Ayrıca Kuzey Kıbrıs Türk Cumhuriyeti'nde de hastalığın yaygın olduğu bildirilmiştir (Hekimhan ve ark., 2016b). Sivrikaya ve ark. (2020) ise Bingöl ilinde inceledikleri 5 tarladan 3'ünün hastalıkla bulaşık olduğunu ve hastalık şiddetinin $\%$ 3-9 arasında değiştiğini bildirmişlerdir.

Dünyada ve ülkemizde son zamanlarda yağış rejimindeki düzensizlikler dikkat çekmektedir. Yağış rejimindeki bu sapmalar, tarımsal üretimi olumsuz yönde etkilemektedir. Yağışların baharın son aylarına doğru kayma göstermesi, arpadaki yaprak leke hastalıklarının etkisini ve yoğunluğunu artırmış, hatta bazı tarlalarda oldukça yoğun oranda hastalık etmeni belirlenmiştir. Özellikle son yıllarda, arpa ekiminin yoğun olduğu yörelerde hastalık daha fazla ve daha şiddetli olarak görülmektedir (Mamluk ve ark., 1997; Yıldırım ve ark., 2000; Karakaya ve ark., 2014; Çelik ve Karakaya, 2015; Hekimhan ve ark., 2016a; Hekimhan ve ark., 2016b; Araz ve Hekimhan, 2017; Öztürk ve ark., 2017). Türkiye'de yapılan çalışmalarda hastalığın İç Anadolu Bölgesinde Ankara, Eskişehir, Konya ve Çorum illerinde 9 patotipi (Araz ve Hekimhan, 2017); Orta Anadolu Bölgesinde 18, Güney Doğu Anadolu Bölgesinde 14, Ege Bölgesinde 6 ve Karadeniz Bölgesinde 1 patotipi ve Türkiye genelinde 30 patotipi belirlenmiştir (Azamparsa, 2015; Azamparsa ve Karakaya, 2020).

Dünyada 1983 yılından bu yana $R$. commune'ye karş1 hemen hemen tüm ülkelerde fungisit kullanımı artmıştır (Sutton ve Steele, 1983; Polley ve King, 1993). Hastalıklarla mücadelede kullanılan kimyasallar üretim maliyetlerini arttırmakla birlikte çevreye ve sağlığa olan olumsuz etkileri de bulunmaktadır. Kimyasal uygulamalar sonucunda ortaya çıkan kalıntılar biyolojik ortamı etkilemekte ve ekosisteme zarar vermektedir. Hastalıklarla mücadelenin en ekonomik ve en uygun yolu 
dayanıklı çeşitler geliştirilerek, bunların üretilmesi ve çiftçinin kullanımına sunulmasıdır (Birişik ve ark., 2015). İç Anadolu Bölgesi'nde yapılan bir çalışmada $R$. commune'nin mücadelesinde $\mathrm{Rh} 4 / 10+$ ? dayanıklılık geni içeren çeşitlerin ekilmesi ve aynı zamanda hastalığa dayanıklılık amacıyla yapılacak çalışmalarda kullanılması önerilmiştir (Araz ve Hekimhan, 2017). Hastalı etmenlerine karşı dayanıklılık 1slahı çalışmaları devamlı olarak sürdürülmeli ve hastalık etmenlerinin fizyolojik değişimi yakından izlenmelidir (Aktaş ve Katırcioğlu, 2008).

Hastalığın virülent patotiplerine karşı yeni tescil ettirilmiş ve ileri kademe arpa 1slah materyallerinin reaksiyonlarının belirlenmesi bu çalışmanın ana amacını oluşturmaktadır. Bu çalışma ile fungusun virülent patotip karışımları ile Türkiye'de kamu, özel sektör ve çeşitli üniversiteler tarafindan tescil ettirilmiş bazı arpa çeşitleri ve ileri kademe arpa hatlarına tarla koşullarında suni inokulasyonlar yapılarak bunların hastalığa karşı dayanıklılık durumlarının belirlenmesi amaçlanmaktadır. $\mathrm{Bu}$ çalışma ile saptanacak dayanıklılık kaynakları ıslah çalışmalarında dayanıklı çeşitlerin geliştirilmesi açısından büyük önem taşımaktadır.

\section{MATERYAL ve METOT}

\section{Materyal}

Çalışmanın ana materyalini, ülkemizde tescilli 63 adet arpa çeşidi ve 2017-2018 sezonunda 23 adet ileri kademe arpa hattı ve 2018-2019 sezonunda da ilk y1ldan farklı 23 adet ileri kademe arpa hattı kullanılarak yürütülmüştür (Çizelge 1,2,3). Her iki yılda farklı hatların kullanılmasının nedeni verim denemelerinde yer alan hatların her yıl değişmesi ve bu hatların hastalığa karşı durumları hakkında ön bilgi elde edinilmek istenmesidir. İnokulasyonlarda kullanılan izolatları yakın zamanda sonuçlanan "Orta Anadolu Bölgesinde arpa ekiliş alanlarında arpa yaprak leke hastalığ 1 "Rhynchosporium secalis [Oudem (J.J. Davis)]"in patotiplerinin belirlenmesi ve mücadele olanaklarının araştırılması" (Proje No: TAGEM-BS-12/12-05/02-15) projesi kapsamında Ankara, Eskişehir ve Konya illerinden elde edilen 5 adet virülent patotipten oluşmuştur.
Denemede Kalayc1-97, Bülbül-89 ve Efes-3 çeşitlerine hassas kontrol (Düşünceli ve ark., 2008; Azamparsa ve ark., 2015; Azamparsa, 2015) ve Avc1-2002 çeşidine (Azamparsa ve ark., 2015) ise dayanıklı kontrol olarak yer verilmiştir.

\section{Metot}

\section{Denemelerin planlanması}

Çalışma; 2017-2018 ve 2018-2019 sezonlarında 63 adet arpa çeşidi, 2017-2018 sezonunda 23 adet ileri kademe arpa hattı ve 2018-2019 sezonunda da ilk yıldan farklı 23 adet ileri kademe arpa hattı kullanılarak yürütülmüştür. Her genotip her blokta $1 \mathrm{~m}$ uzunluğundaki sıralara sıra arası $45 \mathrm{~cm}$ aralık bırakılarak tarlaya ekilmiştir. Denemeler 3 tekerrürlü olarak Tesadüf Blokları Deneme Deseninde her iki yılda Ekim ayının ilk haftasında Eskişehir'de Geçit Kuşağı Tarımsal Araştırma Enstitüsü deneme arazisinde kurulmuştur. Deneme alanı olarak her iki yılda da aynı arazi, yarısı diğer yıl ekilmek üzere boş bırakılarak kullanılmıştır.

\section{İnokulumunun hazırlığı ve inokulasyon}

İnokulasyon çalışmaları için $-80{ }^{\circ} \mathrm{C}$ 'de depolanan fungusun önceki çalışmalarda belirlenen 5 adet virülent patotipinin tek spor izolatları ayrı ayrı PDA (Patates Dekstroz Agar) ortaminda geliştirilmiştir. Petrilere çizim yapılarak ekimi yapılan kültürler, $14-20$ gün süre ile $17-20{ }^{\circ} \mathrm{C}$ ' de karanlık ortamda inkübe edilerek koloni oluşumu sağlanmıştır (Salamati ve Tronsmo, 1997; Arabi ve ark., 2019). Gelişen $R$. commune kolonileri steril su ve firça yardımıyla kazınmış, tülbentten süzülerek konidi inokulumu hazırlanmıştır. Beş adet virülent patotip için ayrı ayrı inokulum hazırlanmış, daha sonra hepsi karıştırılmıştır. İnokulum spor konsantrasyonu; ml'de $2 \times 10^{5}$ spor/ml bulunacak şekilde ayarlanmıştır (Salamati ve Magnus, 1997, Tronsmo, 1997). Bitkilere kardeşlenme dönemi sonu sapa kalkma başlangıcında akşamüstü saatlerinde bir hafta içerisinde üç kere inokulasyon yapılmıştır. Bir dekara 50 litre inokulum kullanılarak, parsellerdeki tüm bitkilere homojen bir şekilde püskürtülmüştür. Üzeri ertesi güne kadar plastik örtüyle kapatılan 
H. HEKIMHAN, O. BÜYÜK, F. ÜNAL, A. ARAZ, A. YOGANCILAR, M. E. ÖZKESKIN, A. TORUN, S. YÜKSEL, E. ÇELIK, S. KAYMAK: TARLA KOŞULLARINDA SUNI INOKULASYON ILE BAZI ARPA GENOTIPLERININ Rhynchosporium commune (ZAFFARANO, MC DONALDS\&LINDE) ARPA YAPRAK YANIKLIĞI HASTALIĞINA KARŞI REAKSIYONLARININ BELIRLENMESİ

bloklarda yeterli hastalık oluşumu ve yayılmasını sağlamak için üzeri açıldıktan sonra akşam saatlerinde 2 saat süreyle yağmurlama sulama (Salamati ve Magnus, 1997) yapılmıştır.

\section{Hastalık değerlendirmeleri}

Hastalık etmeninin değerlendirilmesi tarlada süt olumu döneminde, Zadoks skalasına göre 71-77. dönemler arasında (Zadoks ve ark., 1974) Saari ve Prescott (1975)'un Cizelge 1'de verilen skalasına göre yapılmıştır (Düşünceli ve ark., 2008). Hastalık değerlendirmelerinde skalaya göre sınıflandırma dikkate alınarak, çeşitlerin hastalık etmenine karşı gösterdiği reaksiyonlar skalada belirtilen dayanıklılık düzeyine göre belirlenmiştir. Parsel sıraları incelenirken bir sıra üzerinde hastalık belirtilerinin görüldüğ̈̈ bitkiler sayılıp toplam bitki sayısına oranlanarak hastalık yoğunluğu tespit edilmiștir.
Eskișehir Merkez İlçesi için ayrıca Meteoroloji Bölge Müdürlüğü'nden iklim verileri temin edilmiştir (Çizelge 2). Çeşitlerin reaksiyon değerlendirmeleri iki sezonun ortalaması üzerinden değil almış olduğu en yüksek skala değeri üzerinden yapılmıştır.

\section{İstatistiksel analizler}

Çalışmadan elde edilen veriler SAS yazılımı JMP Pro 13.0.0 (64 bit) paket programı (Anonymous, 2016) kullanılarak analiz edilmiştir. Tesadüf Blokları Deneme Desenine göre üç tekerrürlü olarak tasarlanan ve varyans analizine tabi tutulan verilerin ortalamaları arasındaki farklılıklar ve gruplandırmalar $\mathrm{P} \leq 0,05$ 'de en küçük önemli fark (LSD) testine göre yapılmıştır (Kalayc1, 2005; Acar ve Gizlenci, 2006). Grafikleri çizmek için Excel programı kullanılmıştır.

Çizelge 1. Arpa çeşit ve hatlarının R. commune'ye karşı gösterdiği reaksiyonların tespitinde kullanılan skala (Saari ve Prescott, 1975).

Table 1. Scale used to determine the reactions of barley cultivars and lines against $R$. commune (Saari and Prescott, 1975).

\begin{tabular}{lll}
\hline $\begin{array}{l}\text { Skala } \\
\text { Scale }\end{array}$ & \multicolumn{1}{c}{$\begin{array}{c}\text { Reaksiyon } \\
\text { Reaction }\end{array}$} & \multicolumn{1}{c}{$\begin{array}{c}\text { Enfeksiyon durumu } \\
\text { Infection status }\end{array}$} \\
\hline 1 & $\begin{array}{l}\text { Çok dayanıklı, İmmun (I) } \\
\text { Very resistant, Immune (I) }\end{array}$ & Hiç hastalık belirtisi yok \\
\hline 2,3 & $\begin{array}{l}\text { Dayanıklı (R) } \\
\text { Resistant (R) }\end{array}$ & Az miktarda (bitki vejetatif aksamının \%1-20 kadarında) hastalık belirtisi var \\
\hline 6,5 & $\begin{array}{l}\text { Orta dayanıklı (MR) } \\
\text { Moderate resistant (MR) }\end{array}$ & $\begin{array}{l}\text { Vejetatif aksamın \%20-50 kadarı enfeksiyonla kaplı, dayanıklılı̆̆ kabul } \\
\text { edilebilir seviyede }\end{array}$ \\
\hline 8,7 & $\begin{array}{l}\text { Hassas (S) } \\
\text { Susceptible (S) }\end{array}$ & Vejetatif aksamın \%50-75 kadarı enfeksiyonlu durumda \\
\hline
\end{tabular}

Çizelge 2. Eskişehir ili 2017-2018 ve 2018-2019 sezonu deneme bölgesi aylık ortalama iklim verileri (Anonim, 2020b). Table 2. Monthly climate average data of trial zone in Eskişehir province for 2017-2018 and 2018-2019 seasons (Anonim, 2020b).

\begin{tabular}{|c|c|c|c|c|c|c|}
\hline \multirow{2}{*}{$\begin{array}{l}\text { Aylar } \\
\text { Months }\end{array}$} & \multicolumn{2}{|c|}{$\begin{array}{c}\text { Nem }(\%) \\
\text { Humidity (\%) }\end{array}$} & \multicolumn{2}{|c|}{$\begin{array}{c}\text { Sicaklik }\left({ }^{\circ} \mathrm{C}\right) \\
\text { Temperature }\left({ }^{\circ} \mathrm{C}\right)\end{array}$} & \multicolumn{2}{|c|}{$\begin{array}{c}\text { Yağış }(\mathrm{mm}) \\
\text { Precipitation }(\mathrm{mm})\end{array}$} \\
\hline & $2017-2018$ & 2018-2019 & $2017-2018$ & 2018-2019 & $2017-2018$ & 2018-2019 \\
\hline Ekim (October) & 68,30 & 69,80 & 11,90 & 14,00 & 34,10 & 25,30 \\
\hline Kasım (November) & 80,30 & 75,00 & 6,70 & 8,40 & 12,90 & 10,20 \\
\hline Aralık (December) & 82,40 & 82,60 & 4,50 & 2,70 & 36,20 & 41,10 \\
\hline Ocak (January) & 83,00 & 80,70 & 2,20 & 1,70 & 32,00 & 40,30 \\
\hline Şubat (February) & 77,50 & 72,10 & 6,60 & 4,10 & 23,20 & 51,70 \\
\hline Mart (March) & 67,10 & 58,60 & 10,10 & 7,30 & 46,20 & 11,60 \\
\hline Nisan (April) & 53,10 & 62,30 & 15,40 & 10,20 & 7,90 & 38,60 \\
\hline Mayıs (May) & 68,50 & 55,70 & 17,60 & 17,50 & 51,80 & 37,90 \\
\hline Haziran (June) & 64,70 & 62,40 & 20,60 & 21,20 & 78,50 & 57,80 \\
\hline
\end{tabular}




\section{BULGULAR ve TARTIŞMA}

Tarla koşullarında suni inokulasyon yöntemi kullanılarak yürütülen çeşit reaksiyon çalışmasında 63 materyal iki yıl süre ile test edilmiştir. Elde edilen sonuçlar Çizelge 3'te verilmiştir. Çeşitlerin hastalığa karşı göstermiş oldukları reaksiyonlar; y1llar arasında ve y1 *çeşit faktörleri arasında istatistiki olarak \%1 seviyesinde farklllıklar göstermiştir. 2017-2018 sezonunda çeşitlerin ortalama skala değerleri $(4,78)$ 2018-2019 sezonu skala değerinden $(3,71)$ daha yüksek olarak gerçekleşmiştir. 2018-2019 sezonunda deneme alanında gelişen diğer hastalıkların [arpa yaprak pas1 (Puccina hordei) ve külleme (Blumeria graminis)] yoğun olarak gelişmesi R.commune'nun oluşturduğu hastalığın biraz daha düşük seviyede gelişmesine neden olduğu düşünülmektedir. Testlenen çeşitlerin R.commune'ye gösterdiği reaksiyonlar Çizelge 3'te verilmiş olup; Hilal (1) çok dayanıklı olarak belirlenmiştir. Avcı-2002 (2) ve Sabribey (3) genotipleri ise dayanıklı olarak reaksiyon göstermişlerdir. Orta derecede dayanıklı reaksiyon gösteren çeşitler; Akar (5), Angora (5), Artemis (5), Aydanhanım (4), Bürküt (5), Cervoise (5), Çetin-2000 (5), Erginel-90 (4), Kral-97 (4), Olgun (5), Ramata (4), Seymen (5) ve Troya (5)'dır. Akhisar-98 (9), Bilgi-91 (9), Epona (8), Martı (8), Özen (9), Samyeli (9), Sladoran (8) ve Zeynelağa (8) çeşitleri ise çok hassas olarak belirlenmiş olup diğerleri hassas (6-7) olarak tespit edilmiştir.

Bazı ileri kademe arpa hatlarına 2017-2018 yılında tarla koşullarında yapılan suni inokulasyonlar sonucu hatların R.commune ye gösterdikleri reaksiyonların skala değerleri arasında istatistiki olarak \%1 seviyesinde farkl111klar tespit edilmiştir. Testlenen 23 genotipten TORRENT/CLERINE (2), SONATA/4/ERG//364TH/TOK/3/ERG (3) ve YUBİLEY 100/ORZA-96 (3) melezleri dayanıklı reaksiyon göstermiştir. Geri kalanlardan 7 adedi hassas ve 13 adedi de orta dayanıklı reaksiyon vermiştir (Çizelge 4).

2018-2019 yılında testlemeye alınan ileri kademe arpa hatlarının suni inokulasyonları sonucunda da bu genotiplerin yaprak lekesi hastalığına ( $R$. commune) karş1 gösterdikleri reaksiyonların skala değerleri arasında istatistiki olarak \%1 seviyesinde farklar tespit edilmiştir. Çizelge 4 incelendiğinde testlenen 23 adet genotipin almış olduğu skala değerleri sonuçlarına göre; BURGAZ/K-304 (3), ERGINEL90/5/4056/GZK//784/3/5548/4/WBELT14 (3), ST4512/ST5816 (2) ve WKN 5185/82// CARLA (3) melezleri dayanıklı reaksiyon göstermiştir. Geri kalan 19 genotipten 3 adedi hassas, 10 adedi orta dayanıklı, 5 adedi de çok hassas reaksiyon vermiş REBELLE/ST5807 (1) melezi ise çok dayanıklı reaksiyon göstermiştir.

Yürütülen çeşit reaksiyon çalışmasında yer alan sette 1 adet çok dayanıklı, 2 adet dayanıklı, 13 adet orta dayanıklı, 38 adet hassas ve 9 adet çok hassas genotip belirlenmiştir. Testlenen ileri kademe arpa hatlarından 2017-2018 y1linda denenen sette ise 3 adet dayanıklı, 13 adet orta dayanıklı ve 7 adette hassas genotip belirlenmiştir. 2018-2019 yılında testlenen sette ise 1 adet çok dayanıklı, 4 adet dayanıklı, 10 adet orta dayanıklı, 3 adet hassas ve 5 adette çok hassas genotip belirlenmiştir. İncelenen mevcut çeşitlerin çoğunluğunun hassas reaksiyon gösterdiği, denemeye alınan verim kademesindeki sslah materyallerinin ise çoğunluğunun orta dayanıklı ve üst seviyede dayanıklı olduğu görülmüştür (Şekil 1). Bu da verim kademesine gelen materyallerin $\mathrm{F}$ kademelerinde yapılan seleksiyonunda R.commune açısından başarılı bir seçim yapıldığını göstermektedir.

Bütün testlenen çeşit ve hatlar değerlendirildiğinde ise toplam olarak 2 adet çok dayanıklı, 9 adet dayanıklı, 36 adet orta dayanıklı, 48 adet hassas ve 14 adet çok hassas genotip belirlenmiştir (Şekil 2). Bunların yüzde dağılımları ise sırasıyla $\% 1,8$ çok dayanıklı, \%8,3 dayanıklı, \%33 orta dayanıkl, $\% 44$ hassas ve \%12,8 çok hassastır (Şekil 3).

Denemenin kurulduğu 2018-2019 sezonunda nem, sıcaklık ve yağış daha düşük olarak gerçekleşmiştir (Çizelge 2). Sıcaklığın özellikle bahar aylarında düşük gitmesi R.commune'nin gelișiminin yavaşlamasına sebep olurken külleme (B. graminis) 
H. HEKIMHAN, O. BÜYÜK, F. ÜNAL, A. ARAZ, A. YOGANCILAR, M. E. ÖZKESKIN, A. TORUN, S. YÜKSEL, E. ÇELIK, S. KAYMAK: TARLA KOŞULLARINDA SUNI İNOKULASYON ILE BAZI ARPA GENOTIPLERININ Rhynchosporium commune (ZAFFARANO, MC DONALDS\&LINDE) ARPA YAPRAK YANIKLIĞI HASTALIĞINA KARŞI REAKSIYONLARININ BELIRLENMESİ

ve arpa yaprak pası (Puccinia hordei) hastalıklarının da artmasına neden olmuştur.

Yürütülen çalışmada 2017-2019 yılları arasında toplam 109 adet arpa genotipi R.commune ile tarla koşullarında test edilerek reaksiyonları belirlenmiştir. 63 materyal iki yıl üst üste testlenmiş diğer iki set ise her y1l değișen verim kademesindeki hatlardan oluşmuş ve birer yıl testlenmiştir (Şekil 1). Bütün testlenen materyaller değerlendirildiğinde toplam olarak 2 adet çok dayanıklı, 9 adet dayanıklı, 36 adet orta dayanıklı, 48 adet hassas ve 14 adet çok hassas genotip belirlenmiştir (Şekil 2).

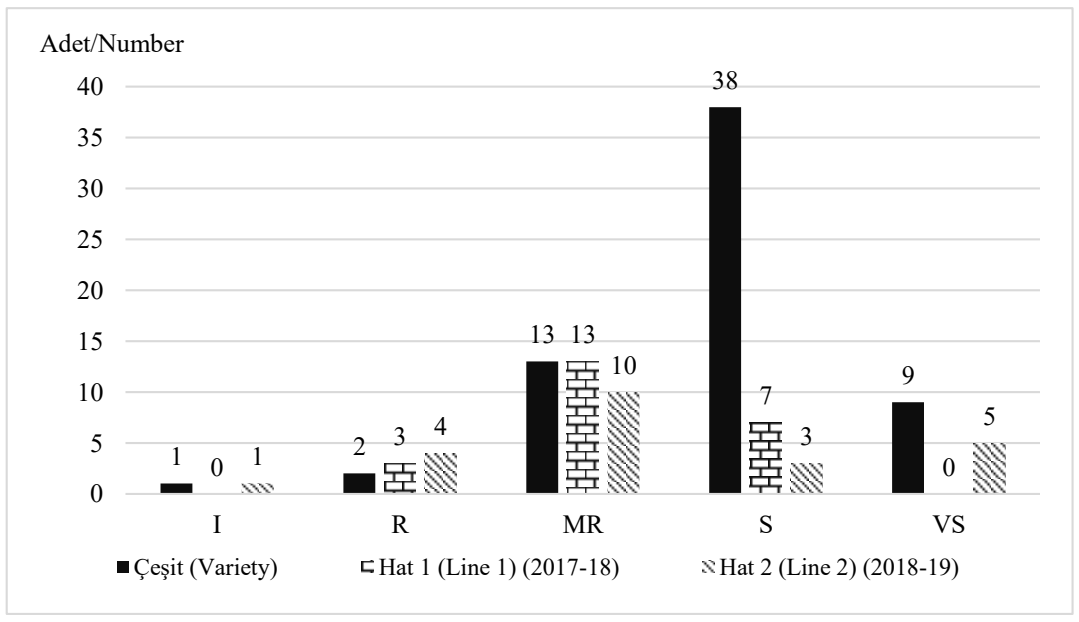

Şekil 1. Testlenen çeşit ve hat setlerinde genotip reaksiyonlarının dağılımları (adet) [(I) Çok dayanıklı, (R) Dayanıklı, (MR) Orta Dayanıklı, (S) Hassas, (VS) Çok Hassas)].

Figure 1. Distributions of genotype reactions determined in tested variety and line sets (number) [(I) Very resistant, (R) Resistant, (MR) Moderate Resistant (S) Susceptible (VS) Very Susceptible].

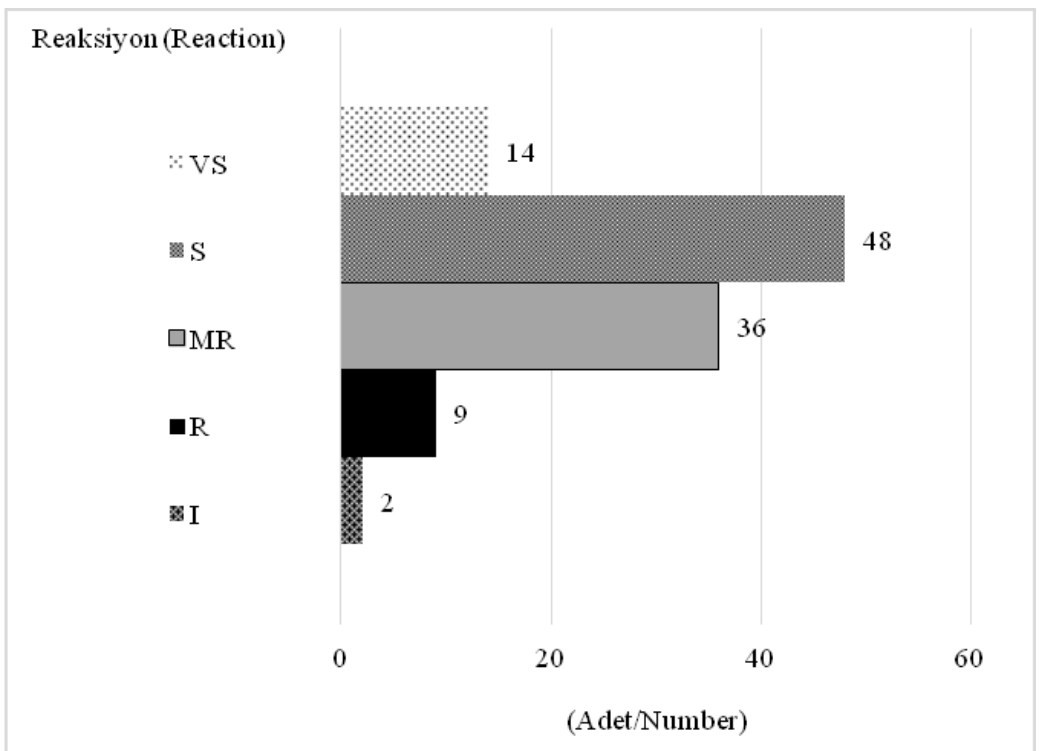

Şekil 2. Tüm genotiplerin verdikleri reaksiyonlara göre dağılımları ((I) Çok dayanıklı, (R) Dayanıklı, (MR) Orta Dayanıklı, (S) Hassas, (VS) Cok Hassas).

Figure 2. The distribution of the all genotypes according to the reactions ((I) Very resistant, (R) Resistant, (MR) Moderate Resistant (S) Susceptible (VS) Very Susceptible). 


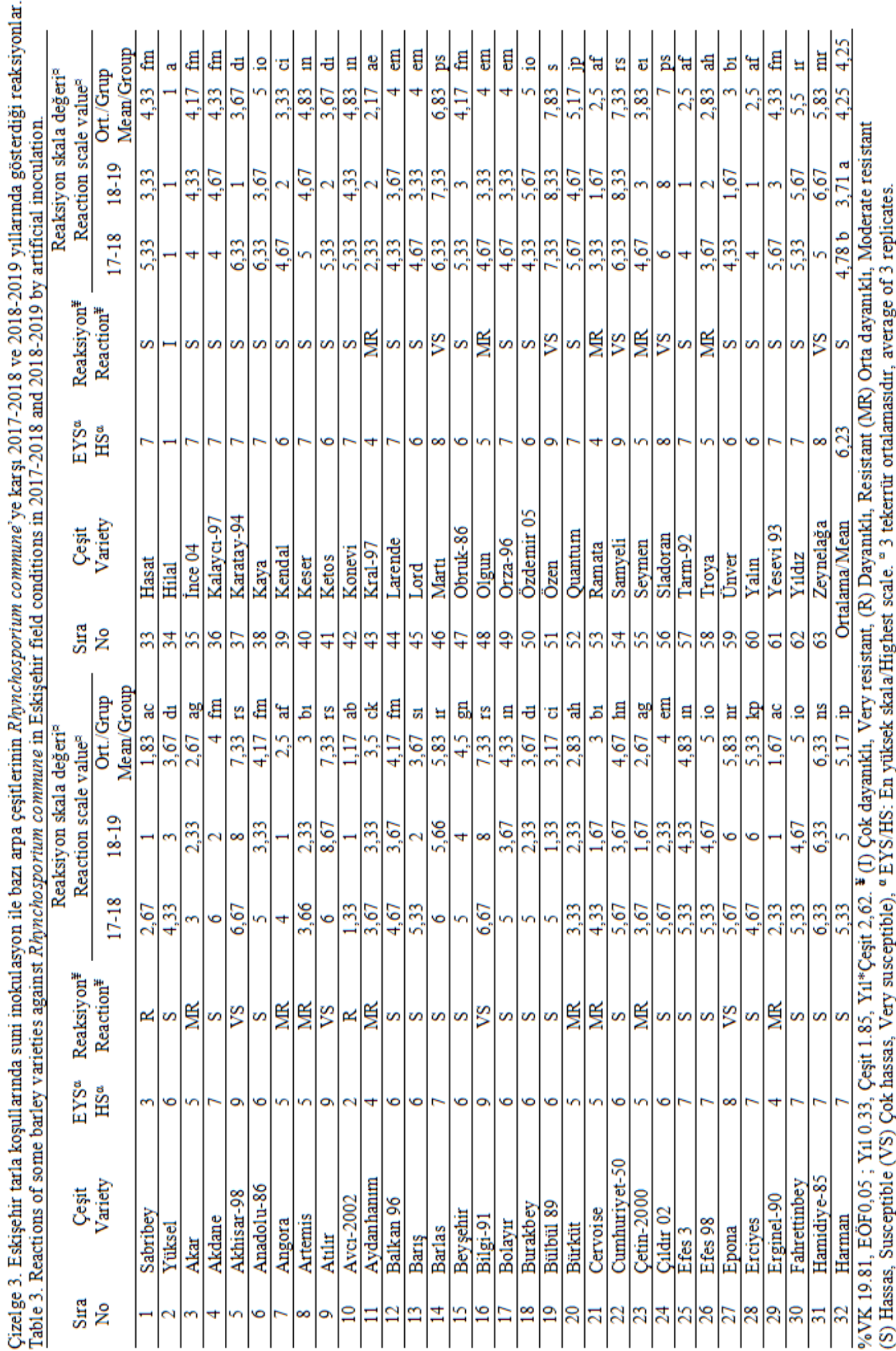


H. HEKIMHAN, O. BÜYÜK, F. ÜNAL, A. ARAZ, A. YOGANCILAR, M. E. ÖZKESKIN, A. TORUN, S. YÜKSEL, E. CELIK, S. KAYMAK: TARLA KOSULLARINDA SUNI INOKULASYON ILE BAZI ARPA GENOTIPLERININ Rhynchosporium commune (ZAFFARANO, MC DONALDS\&LINDE) ARPA YAPRAK YANIKLIĞI HASTALIĞINA KARŞI REAKSIYONLARININ BELIRLENMESİ

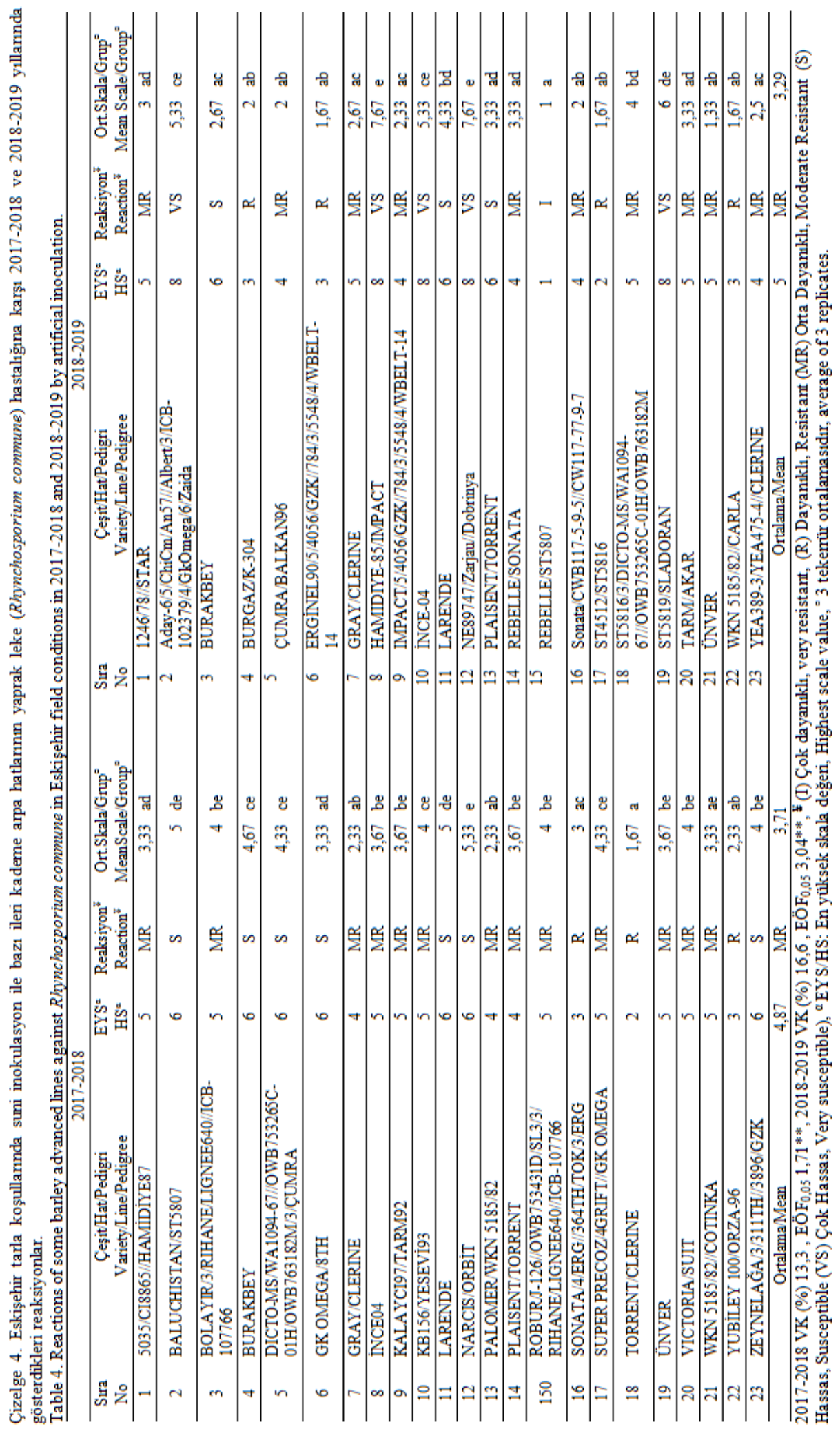




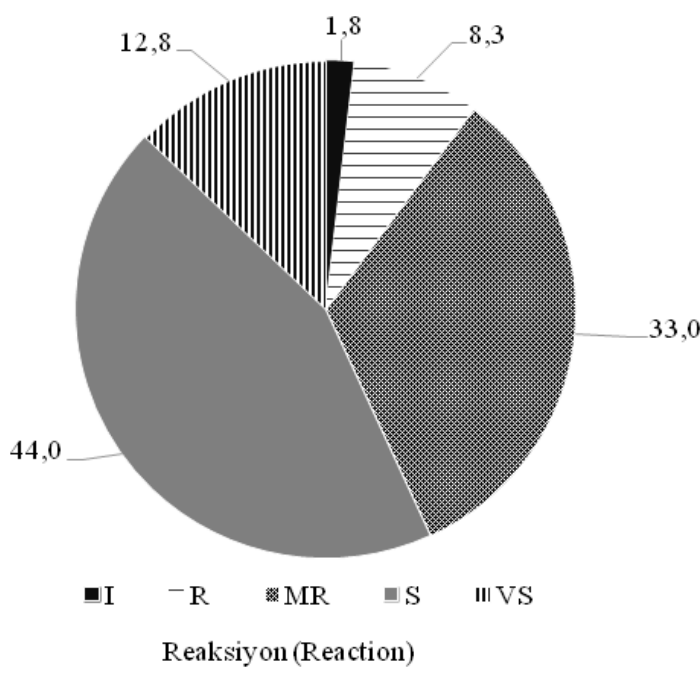

Şekil 3. Tüm genotiplerin reaksiyonlarına göre oransal dağılımları (\%) ((I) Çok dayanıklı, (R) Dayanıklı, (MR) Orta dayanıklı, (S) Hassas, (VS) Çok hassas).

Figure 3. The proportional distribution of the all genotypes according to the reactions (\%) (I) Very resistant, (R) Resistant, (MR) Moderate resistant, (S) Susceptible, (VS) Very susceptible).

Bunların yüzde dağılımları ise sırasıyla $\% 2$ çok dayanıklı, \%8 dayanıklı, \%33 orta dayanıklı, \%44 hassas ve \%13 çok hassas' tır (Şekil 3). Çok dayanıklı, dayanıklı ve orta dayanıklı materyallerin yüzdesi $\% 43$ ve hassas ve çok hassas materyallerin toplamı ise \%57'dir. Albustan ve ark. (1999) 1216 hattan 33 tanesinin hem arpa çizgili yaprak lekesi hem de arpa yaprak lekesi hastalıklarına karşı ikili dayanıklılık özelliği taşıdıklarını belirlemişler, Düşünceli ve arkadaşları (2008) 683 arpa hattından tarla ve sera testlemelerine göre materyalin \%44'ünü sera koşullarında ve \%39'unu da tarla koşullarında yaprak yanıklık hastalığına karşı dayanıklı bulmuşlardır. Mert ve ark.(2009) ise 88 genotipten 9'unun (\%10) kabul edilebilir seviyede dayanıklılık gösterdiğini ve yine Mert ve ark. (2014) 200 materyalden 5 adedini dayanıklı olduğunu bulmuşlardır. $\mathrm{Bu}$ veriler çalışmamızın sonuçları ile benzerlik göstermektedir.

Çalışmamızda Hilal çeşidi (1) ve REBELLE/ ST5807 melezi (1) çok dayanıklı olarak belirlenmiştir. Sabribey (3) ve Avc1-2002 (2) çeşitleri ile TORRENT/CLERİNE (2), SONATA/4/ ERG//364TH/TOK/3/ERG (3), YUBILEY 100/
ORZA-96 (3), BURGAZ/K-304 (3), ERGINEL90/) 5/4056/GZK//784/3/5548/4/WBELT-14 (3), ST4512/ ST5816 (2), WKN 5185/82//CARLA (3) melezleri ise dayanıklı olarak reaksiyon göstermişlerdir. $\mathrm{Bu}$ materyaller 1slahta dayanıklılık kaynağ 1 olarak kullanılabilirler ayrıca hastalığın yoğun olarak görüldüğü ve problem olan alanlarda Hilal çeşidi yazlık kesimlere ve Sabribey ve Avc1-2002 çeşitleri ise kışlık kesimlere tavsiye edilebilir.

Ülkemizde yürütülen diğer çalışmalarda Mert ve Karakaya (2004) ile Düşünceli ve ark, (2008) da Erginel-90, Kıral-97, Çetin-2000, Avc1 2002 çeşitlerini yürüttüğümüz çalışmada olduğu gibi dayanıklı bulmuşlardır. Ancak denemelerde ortak yer alan Akhisar-98, Kaya-7794 çeşitlerini araştırmacılar yüksek derecede dayanıklı bulurken çalışmamızda ise bu çeşitler hassas olarak belirlenmiştir. Azamparsa ve ark. (2015) ve Azamparsa (2015) da çalışmamızda olduğu gibi Avc1-2002 çeşidini dayanıklı olarak, Kalaycı-97 ve Bülbül-89 çeşitlerini de hassas olarak tespit etmişlerdir. Kavak (1998) Efes-3 çeşidini yaptığ 1 çalışmada dayanıklı bulurken çalışmamızda ve Düşünceli ve ark (2008) ile Azamparsa ve ark. (2015)'nın yürüttüğü çalışmada ise hassas olarak belirlenmiştir. Nitekim Cromey ve ark. (1999) değerlendirme zamanlarının çeşitlerin reaksiyonlarının belirlenmesinde farklılıklar gösterdiğini bildirmektedirler. Nitekim seksüel dönemi olmamasına rağmen, $R$. commune popülasyonları yüksek derecede genetik varyasyona sahip olduğundan hastalık etmenine karşı düzenli olarak güncel patotiplerinin ve bu patotiplerle arpa çeşitlerinin reaksiyonlarının belirlenmesi gerektiği de vurgulanmaktadır (Xue ve ark. 1991; Jorgensen ve Smedegaard-Peterson, 1995; Araz ve Maden, 2006; Araz ve Hekimhan, 2017). Brown (1990) ise farklı veya aynı bölgelerden toplanmış olan ve farklı lezyonlardan elde edilmiş izolatlar arasındaki patojenik varyasyon ile aynı lezyonlardan elde edilmiş tek spor izolatları arasında da patojenik varyasyon olarak çok fazla fark olduğunu belirtmiştir.

Yürütmüş olduğumuz çalışmada denemenin kurulduğu 2018-2019 sezonunda hastalık skorları 
daha düşük olarak gerçekleşmiş, çeşitlerin reaksiyonlarında değişimler görülmüştür. Bunun sebeplerinin; iklim, patojenler aras1 rekabet ve dayanıklılığın teşviki olduğu düşünülmektedir. Sicaklığın özellikle bahar aylarında düşük gitmesi $R$. commune' nin gelişiminin yavaşlamasına sebep olurken külleme (B. graminis) ve arpa yaprak pası (Puccinia hordei) hastalığının da artmasına neden olmuştur. Bu da o sezonda nem, sıcaklık ve yağışın daha düşük olarak gerçekleşmesinden kaynaklanmıştır. İklim faktörlerinden herhangi birinde oluşan değişiklikler, bitki patojenlerinin dağılımını ve biyolojisini olumlu, olumsuz veya nötr etkileyebilmektedir (Mansouri ve ark., 2014). Nitekim Araz ve ark. (2017) 2014 yılında 2013 y1lına göre hastalığın kurak geçen sezondan dolayı daha düşük seyrettiğini bildirmektedir. Brown (1991), Mansouri ve ark. (2014), Karimi ve Khaledian (2016)'da yıllar itibar1 ile genotiplerin farklı reaksiyon gösterdiğini ve bunun meteorolojik dalgalanmalardan kaynaklandığını bildirmektedirler. Enfeksiyon bölgeleri için hastaliklar (Pyrenophora teres ve $R$. commune) arasındaki rekabet ve bitki yaprağındaki kolonizasyonları sırasında, bitkide hastalıkların farklı gelişimine katkıda bulunabildiği ve bu ilişkinin, iki patojen arasındaki rekabete bağlandığı belirtilmiştir (Cherif ve ark., 2007; Xi ve ark., 2008). Ayrıca daha önce bitkinin konukçusu olmadığ örneğin buğdaydan Septaria nodorum ve misırdan Bipolaris maydis tarafindan etkilenen arpalarda yaprak lekesinin engellenmesinde indüklenen direnç yani dayanıklılı̆̆ın teşviki birincil mekanizma olarak kabul edilmiştir (Jargensen ve ark.,1998).

Çok dayanıklı ve dayanıklı materyal oranının düşük (\%10) olmasının, islahta seleksiyonun hastalıklar dışındaki diğer verim ve verim öğeleri ile kalite özelliklerinin de dikkate alınarak yapılmasından dolayı gerçekleştiği düşünülmektedir. $\mathrm{Bu}$ yüzden hastalık testlerinin daha önceki alt kademelerde yapılarak verim kademesindeki materyallerin dayanıklılık oranının artması sağlanabilir ve tescil edilen materyallerde dayanıklılık oranı artırılabilir. Tarla çalışmaları sonucunda testlenen pek çok materyal içerisinde tespit edilen hassas genotipler çıkarılarak; dayanıklı, yüksek dayanıklı ve orta dayanıklı bulunanların kontrollü koşullarda test edilmesi ve moleküler çalışmalar ile desteklenmesinin uygun olacağı düşünülmektedir. Zira tarla koşullarında diğer canlı ve cansız stres faktörleri genotiplerin reaksiyonlarında değişikliklere sebep olmaktadır.

\section{TEŞEKKÜR}

T.C. Tarım ve Orman Bakanlığı, Tarımsal Araştırmalar ve Politikalar Genel Müdürlüğü ve Eskişehir Geçit Kuşağı Tarımsal Araştırma Enstitüsü Müdürlüğü'ne TAGEM/BSAD/E/17/ $\mathrm{A} 2 / \mathrm{P} 4 / 223$ proje numaras 1 ile desteklerinden dolayı teşekkür ederiz.

\section{LITTERATÜR LISSTESI}

Acar, M., ve Ş. Gizlenci. 2006. Tarımsal Araştırmacılar İçin JMP Kullanımı. Karadeniz Tarımsal Araştırma Enstitüsü. Samsun.

Aktaş, H. 1984. Spread of leaf spots in barley growing areas in Turkey. pp. 338-341. In: Proc. 6th Congr. Un. Phytopath. Mediterr. Cairo, Egypt.

Aktaş, H. 2001. Önemli hububat hastalıkları ve survey yöntemleri. Tarımsal Araştırmalar Genel Müdürlüğü Yayını, Tarım Ve Köyişleri Bakanlığı Tarımsal Araștırmalar Genel Müdürlüğü Bitki Sağlığ Araştırmaları Daire Başkanlığı, Bağdat Cad. No: 208, Pk78, 06171 Yenimahalle-Ankara.

Aktaş, H., ve Z. Katırcıoğlu. 2008. Bazı buğday ve arpa çeşit ve hatlarının önemli bazı fungal patojenlere karşı reaksiyonları. Tarım Bilimleri Dergisi 14(4): 381-385.

Albustan, S., L. Çetin, F. Düşünceli, H. Tosun, ve T. Akar, 1999. Orta Anadolu Bölgesi için TARM tarafindan oluşturulan 1998 yılı arpa nörserilerinin yaprak lekesi [Rhynchosporium secalis (Oud.) J.J. Davis)] ve arpa çizgili yaprak lekesi (Pyrenophora graminea) hastalıklarına karşı dayanıklılık bakımından değerlendirilmesi. Orta Anadolu'da Hububat Tarımının Sorunları Ve Çözüm Yolları Sempozyumu. 8-11 Haziran 1999. Konya. s.700-704.

Anonim. 2020a. http://www.tuik.gov.tr/PreTablo.do?alt_id= 1001(Ziyaret Tarihi 26.08.2020). 
Anonim. 2020b. Eskişehir Meteoroloji 3. Bölge Müdürlüğü.

Anonim. 2006. Devlet planlama teşkilatı müsteşarlığı, dokuzuncu kalkınma planı (2007-2013), (içki, tütün ve tütün ürünleri sanayii özel ihtisas komisyonu raporu2006).

Anonymous. 2016. JMP® Pro 13.0.0, Copyright $(\subset)$ 2016, SAS Institute Inc., Cary, NC, USA.

Anonymous. 2020. Food and Agriculture Organization of United Nations (FAO) Datas http://www.fao.org/ faostat/en/\#data/TP (Ziyaret tarihi 11.01.2021).

Anonymous. 2021. Rhynchosporium Leaf blotch or Scald of winter barley (causal agent Rhynchosporium commune). Croprotect. Copyright 2021. https://croprotect.com/diseases/rhynchosporium-1.

Arabi, M. I. E., H. Alek, E. Al-Shehadah, and M. Jawhar. 2019. Viability and pathogenicity of Rhynchosporium secalis after long-term storage. Acta Phytopathologica et Entomologica Hungarica 54 (1): 127-134, DOI: 10.1556/038.54.2019.011

Araz, A. ve S, Maden. 2006. Pathogenic variation among isolates of Rhynchosporium secalis from cultivated barley growing in Central Anatolia, Turkey. Plant Pathology Journal 5 (2): 244-247

Araz, A., and H. Hekimhan. 2017. Determination of pathotypes of barley scald disease [Rhynchosporium commune (Zaffarano, Mcdonald\&Linde)] in some provinces in central Anatolia. p163. In: II International Iğdır Symposium, 9-11 October. Iğdır-Turkey.

Araz A., O. Büyük, and H. Hekimhan. 2017. Prevalence of the barley scald [Rhynchosporium commune (Zaffarano, Mcdonald\&Linde)] disease in Ankara, Konya and Eskişehir provinces of Central Anatolian Region. pp. P23. In: II. International Iğdır Symposium. 9-11 October. Iğdır-Turkey.

Avrova, A., and W. Knogge. 2012. Rhynchosporium commune: a persistent threat to barley cultivation. Molecular Plant Pathology 13: 986-997.

Azamparsa, M.R. 2015. Türkiye'de Rhynchosporium commune'nin patotiplerinin belirlenmesi ve baz1 yerel arpa çeşitlerine ve yabani arpa (Hordeum spontaneum) populasyonlarına karşı tepkilerinin değerlendirilmesi. Doktora tezi. Ankara Ü. Fen. Bil. Enst. Bitki Koruma Anabilimdalı. Ankara.

Azamparsa, M.R., Z. Mert, A. Karakaya, İ. Sayım, E. Namuk, ve S. Aydoğan. 2015. Bazı arpa çeşitlerinin ve ileri kademe arpa hatlarının Rhynchosporium commune'ye fide dönemi tepkilerinin belirlenmesi. Bitki Koruma Bülteni 55 (3): 247-252.

Azamparsa, M. R., and A. Karakaya. 2020. Determination of the pathotypes of Rhynchosporium commune (Zaffarona, McDonald \& Linde) in some regions of Turkey. Bitki Koruma Bülteni 60(3): 5-14. https://doi.org/10.16955/bitkorb.460235.
Başgül, A., ve A. Engin. 1995. Efes pilsen arpa araştırma ve geliştirme çalışmaları. Arpa-Malt Sempozyumu-III, 57 Eylü 1995. Konya. s. 69-92.

Birişik, N, Y. Bayram, M. Kılıç, Ç. Mutlu, A. Öğreten, S. Eren, M. Kaplan, İ. E. Süer, B. Baran, K. Duman, V. Karaca, M. Duman, O. Çiftçi, Ş. Türkölmez, A. Peçen, P. Sağır, G. Yatkın, B. Güler, C. Kaya, Y. Çelik, A. B. Orak, B. Yaman, ve E. Ateș. 2015. Teoriden Pratiğe Kültürel Mücadele (Editör Dr.Nevzat Birişik). Gıda Tarım ve Hayvancilık Bakanlığı, Gida ve Kontrol Genel Müdürlüğü. 285 sayfa. ISBN: 978-605-917521-0, Ankara.

Birişik, N. 2020. Covid-19 salgınının tarım ve gıda sektörüne olası etkileri ile alınabilecek tedbirler üzerine bir değerlendirme. Gelard 7 (2), ISSN: 2645-8756, 15-19.

Blum, A. 2018. Plant Breeding For Stress Environments. 231pages. CRC Press.

Brown, J.S. 1990. Pathogenic variation among isolates of Rhynchosporium secalis from barley grass growing in shout eastern Australia. Euphytica 50 (1): 81-89.

Brown, J.S. 1991. Definition of infection period for field infection of scald in Victoria (Australia). Australian Journal Of Agricultural Research 42: 811-818.

Cherif, M., S. Rezgui, P. Devaux, and M. Harrabi. 2007. Interaction between Rhynchosporium secalis and Pyrenophora teres in the field and identification of genotypes with double resistance in a double-haploid barley population. J. Phytopathol. 155: 90-96.

Cromey, M.G., R. Hanson, and K.I. Sinclair. 1999. Resistance of New Zealand barley cultivars to scald, caused by Rhynchosporium secalis. pp. 182 -186 In: Proc. 52nd N.Z. Plant Protection Conf..

Çelik, E., ve A. Karakaya. 2015. Eskişehir ili arpa ekim alanlarında görülen fungal yaprak ve başak hastalıklarının görülme sıklıklarının ve yoğunluklarının belirlenmesi. Bitki Koruma Bülteni, $55: 157-170$

Damgac1, E. 1981. Orta Anadolu bölgesi arpa ekilişlerinde Rhynchosporium yaprak lekesi (R. secalis (Oud.) J. J. Davis) hastalığı üzerine araştırmalar, Zirai Mücadele Araştırma Yıllığ 101-102.

Döken, M. T. 1979. Erzurum'da arpadan izole edilen Rhinchosporium secalis (Oudem.) J. J. Davis'in morfolojisi, biyolojisi, zarar durumu ve savaş yöntemleri üzerinde araştırmalar. Doçentlik Tezi. Atatürk Üniv. Zir. Fak. Bitki Koruma Bölümü, Erzurum.

Düşünceli, F., L. Çetin, S. Albustan, Z. Mert, K. Akan, and A. Karakaya. 2008. Determination of the reactions of some barley cultivars and genotypes to scald under greenhouse and field conditions. Tartm Bilimleri Dergisi 14 (1): 46-50. 
Eğilmez, D. ve N. Boyraz. 2019. Aksaray ili buğday ve arpa ekim alanlarındaki fungal hastalıkların son yıllardaki görünümü üzerine bir araştırma. Bahri Dağdaş Bitkisel

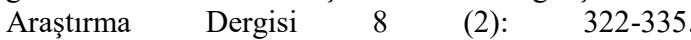
https://dergipark.org.tr/tr/pub/bdbad/issue/51255/6672 51.

Gaunt R.E., and A.C. Wright. 1992. Disease-yield relationship in barley. I1. Contribution of stored stem reserves to grain filling. Plant pathology. 41: 688-701.

Göbelez, M. 1964. La mycoflore de Turque II. Mycopathologia Applicata, 23 (1) :47-67.

Hekimhan, H., A. Konuksal, H. Fıdan, C. Gözüaçık, M. Gullu, R. Değirmenci, and E. Akerzurumlu, E. 2016a. Important fungal disease problems of cereal production areas in Turkish Republic of Northern Cyprus and solution offers. pp. 557. In: VII. International Scientific Agriculture Symposium, "Agrosym 2016", Jahorina, 6-9 October. Jahorina, Bosnia and Herzegovina.

Hekimhan, H., R. Gencer, S.N. Celık, A. Imamoglu, S. Pelit, Y. Eğerci, and A. Kalın. 2016b. Incidence of some fungal diseases of barley production areas in the aegean costal region. pp. 559. In: VII International Scientific Agriculture Symposium, "Agrosym 2016", Jahorina, 6-9 October. Jahorina, Bosnia and Herzegovina.

Hekimhan, H., Araz, A., Aydoğdu, M., 2017. Differences in virulence of Rhinchosporium commune isolates from Central Anatolia on barley cultivars. Journal of Agricultural, Food and Environmental Sciences (JAFES) 71 (2): 110-116. ISSN 2545-4315. Scopje, Macedonia.

Jargensen, H.J.L., P.S., Liibeck, H. Thordai-Christensen, E. de Neergaard, and V. Smedegaard-Petersen. 1998. Mechanisms of induced resistance in barley against Drechslera teres. Phytopathology, 88: 698-707

Jorgensen, H.J.L., and V. Smedegaard-Petersen. 1995. Pathogenic variation of Rhynchosporium secalis in Denmark and sources of resistance in barley. Plant Disease 79: 297-301.

Kalayc1, M. 2005. Örneklerle Jump Kullanımı ve Tarımsal Araştırma İçin Varyans Analiz Modelleri. Anadolu Tarımsal Araştırma Enstitüsü Müdürlüğü Yayınları, Yayın No: 21. ISBN: 975-407-173-X.

Karakaya, A., Z. Mert, A.Ç. Oguz, M.R. Azamparsa, E. Çelik, K. Akan, and L. Çetin. 2014. Current status of scald and net blotch diseases of barley in Turkey. pp 31. In: 1st International Workshop On Barley Leaf Diseases, Salsomaggiore Terme.03-06 June. Italy.

Karimi, K., and M.S. Khaledian. 2016. Field assessment of reaction and yield of some barley genotypes under natural inoculums of Rhynchosporium commune, ejpau 19(4), 10 sayfa, \#03. Available online: http:// www.ejpau.media.pl/volume19/ issue4/art-03.html.

Kavak, H. 1998. Şanlıurfa yöresinde ekimi yapılan bazı arpa çeşitlerinin arpa yaprak lekesine (Rhynchosporium secalis (Oudem.) J.J. Davis) karşı reaksiyonları ve hastalık şiddeti ile verim arasındaki ilișkinin belirlenmesi. Doktora tezi. Gaziosmanpaşa Üniversitesi, Fen Bilimleri Enstitüsü Bitki Koruma Ana Bilim Dalı. Tokat.

Kavak, H., and Z. Katırcığlu, Z. 1998. Arpa Yaprak Yanıklığı (Rhynchosporium secalis (Oud.) Davis)'nın arpada farklı enfeksiyon şiddetine bağlı olarak meydana getirdiği verim kayıplarının belirlenmesi. Türkiye VIII. Fitopatoloji Kongresi. Ankara. s. 34-38.

Mamluk, O.F., L. Çetin, H. J. Braun, N. Bolat, L. Bertschinger, K. M. Makkouk, A. F. Y1ldırım, E. Saari,E., Zencirci, N., Albustan, S., Çalı, S., Beniwal, S. P. S., and Düşünceli., F. 1997. Current status of wheat and barley diseases in the Central Anatolian Plateau of Turkey. Phytopathol. Med. 36: 167-81.

Mansouri, S., I. Radhouane, I., and Abidi. 2014. Climate change impacts on barley diseases in the béja region of North-Western Tunisia. pp 54. In: International Workshop On Barley Leaf Diseases. Salsomaggiore Terme, 03-06 June. Italy.

Mathre, D.E. 1982. Compendium of barley diseases. Aps Press.

Mert, Z., and A. Karakaya. 2004. Assessment of the seedling reactions of turkish barley cultivars to scald. Journal of Phytopathology 152 (3): 190-192.

Mert, Z., A. Karakaya, A.C. Oguz, M.R. Azamparsa, N. Ergun, and I. Sayım. 2014. Field evaluation of some turkish barley landraces to scald and net blotch of barley. pp 65. In: 1st International Workshop On Barley Leaf Diseases. Salsomaggiore Terme. 03-06 June. Italy.

Mert, Z., K. Akan, L. Çetin, A. Yorgancılar, R. Ünsal, B. Ercan, İ. Özseven, M.E. Bayram, N. Dinçer, H. Kılıç, H.O. Bayramoğlu, H. Hekimhan, A. Tülek, D. Güven, ve A. İlkhan. 2009. Buğday ve arpanın ülkemizde görülen bazı önemli hastalıklarına karşı 2008 yılı entegre dayanıklılık ıslahı çalışmaları. Türkiye VIII. Tarla Bitkileri Kongresi, 18-22 Ekim. Hatay. s. 849853.

Öztürk, İ , T. Kahraman, R. Avcı, V. Girgin, T.H., Çiftçigil, A. Tülek, K.Akın, ve B. Tuna. 2017. Arpa genotiplerinde (Hordeum vulgare L.) farklı çevre koşullarının agronomik karakter ve yaprak hastalıkları üzerinde etkisi. Bahri Dağdaş Bitkisel Araştırma Dergisi, 6 (1): 48-56. https://dergipark. org.tr/tr/pub/bdbad/issue/37068/426234.

Polley, R. W., and J. E. E. King,. 1993. Surveys of diseases of spring barley in England and Wales, 1976-1980. Annals of Applied Biology 123: 271-285.

Saari, E. E., and J. M. Prescott. 1975. A scale for appraising 
the foliar intensity of wheat diseases. Plant Dis. Reporter 59: 377-380.

Salamati, S., and H. A. Magnus. 1997. Leaf blotch severity on spring barley infected by isolates of $R$. secalis under different temperature and humidity regimes. Plant Pathology (Oxford) 46: 939-945.

Salamati, S. and A. M. Tronsmo. 1997. Pathogenicity of Rhynchosporium secalis isolates from Norway on 30 cultivars of barley. Plant Pathology 46: 416-424.

Seifollahi, E., B. Sharifnabi, M. Javan-Nikkhah, and C. C. Linde. 2020. Scald on gramineous hosts in Iran and their potential threat to cultivated barley. Mycological Progress 19: 223-233.

Sivrikaya I. S., A. Karakaya, and A. Ç. Oğuz. 2020 Determination of the Barley Diseases in Bingöl Province of Turkey. In: M. Brka, E. OmanovićMikličanin, L. Karić, V. Falan, A. Toroman (Eds). 30th Scientific-Experts Conference of Agriculture and Food Industry. AgriConf 2019. IFMBE Proceedings, vol 78. Springer, Cham.

Sutton J.C., and P. Steele. 1983. Effect of seed and foliar fungicides on progress of netblotch and yield in barley. Can. J. Plant Sci. 63: 631-639.

Xi, K., C. Bos, T.K. Turkington, A.G. Xue, P.A. Burnett, and P.E. Juskiw. 2008. Interaction of net blotch and scald on barley, Canadian Journal of Plant Pathology 30 (2): 329-334. DOI: 10.1080/07060661.2008.10540548
Xue, B., R. Hall, and D. Falk, 1991. Pathogenic variation in Rhynchosporium secalis from Southern Ontario. Pl. Disease 75: 934-938.

Yıldırım, A. F., E. Kınacı, H. Hekimhan ve S. Çeri. 2000. Konya, Karaman, Niğde ve Aksaray yörelerinde tahıllarda önemli hastalıkların durumu ve bunlara dayanıklılık kaynaklarının araştırılması. Orta Anadolu'da Hububat Tarımının Sorunları Ve Çözüm Yolları Sempozyumu. Konya. s. 404-413,

Zadoks, J. C., T. T. Chang, C.F. Konzak. 1974. A decimal code for the growth stages of cereals. Weed Research 14: 415-421.

Zaffarano P. L., B. A., Mcdonald and C. C. Linde. 2011. Two new species of Rhynchosporium. Mycologia 103 (1): 195- 202.

Zencirci, N., and P. M. Hayes. 1990. Effect of scald (Rhynchosporium secalis) on yield components of twelve winter barley genotypes. Journal of Turkish Phytopathology 82: 798-803. 